\title{
RANCANG BANGUN MEDIA PEMBELAJARAN BANGUN RUANG AUGMENTED REALITY BERBASIS ANDROID PADA SMP NEGERI 8 PALOPO
}

\author{
Andi Nurul Mutia ${ }^{1 *}$, Apriyanto $^{2}$, Ahmad Ali Hakam Dani ${ }^{3}$ \\ ${ }^{123}$ Program Studi Teknik Informatika, Fakultas Teknik, Universitas Andi Djemma, Jl. \\ Tandipau, Tomarundung, Palopo 91913 Indonesia
}

\begin{abstract}
ABSTRAK
Tujuan dari penelitian ini adalah untuk mengembangkan aplikasi yang dapat membantu siswa SMP dalam memahami obyek bangun ruang pada mata pelajaran matematika dan mengetahui tingkat kelayakan aplikasi yang dikembangkan ditinjau dari aspek functional dan usability. Penelitian dan pengembangan aplikasi menggunakan metode penelitian Research and Development $(R \& D)$ yaitu metode penelitian yang bertujuan menghasilkan produk tertentu serta menguji efektivitas produk tersebut. Produk dikembangkan dengan menggunakan metode waterfall proscess model. Model pengembangan perangkat lunak waterfall memiliki enam tahapan, yaitu system enginering (perancangan sistem), analysis (analisis), design (perancangan), coding (pengkodean), testing (pengujian) dan maintenance (pemeliharaan). Aplikasi media pembelajaran bangun ruang ini menggunakan Unity $3 D$ diuji melalui metode Black Box Testing dan pengujian kuesioner. Dengan adanya aplikasi pembelajaran tersebut dapat membantu guru dalam mengajarkan materi bangun ruang melalui media aplikasi sehingga proses belajar lebih interaktif dan sebagai alternatif lain bagi siswa untuk belajar materi bangun ruang di luar sekolah.
\end{abstract}

Kata Kunci: Bangun Ruang, Research and Development, Waterfall, Blackbox, Unity 3D

\section{PENDAHULUAN}

Kemajuan teknologi saat ini di dunia pendidikan memerlukan usaha yang maksimal untuk dapat menghasilkan peserta didik yang berkualitas guna menghadapi ilmu pengetahuan dan teknologi. Pemanfaatan teknologi smartphone dalam bidang pendidikan salah satunya adalah digunakan sebagai media pembelajaran. Media pembelajaran secara umum adalah alat bantu proses belajar mengajar. Segala sesuatu yang dapat dipergunakan untuk merangsang pikiran, perasaan, perhatian dan kemampuan atau ketrampilan pebelajaran sehingga dapat mendorong terjadinya proses belajar.

Pelaksanaan kegiatan belajar mengajar yang dilakukan di dalam kelas sering ditemukan masalah, antara lain guru yang menganggap siswa hanyalah benda yang 
dapat menerima pembelajaran dari gurunya saja, serta banyaknya materi pelajaran yang harus dipelajari siswa. Selain itu, guru juga kurang terbiasa menggunakan media pembelajaran yang bervariasi.

Matematika merupakan mata pelajaran yang penting dalam dunia pendidikan karena matematika mencakup kesegala aspek kehidupan, kita tidak bisa terlepas dari matematika dalam kehidupan sehari-hari seperti menghitung, menentukan bentuk, menentukan ukuran dan lainnya, sehingga matematika hukumnya wajib untuk dipelajari. Namun, sebagian siswa masih menganggap Matematika sebagai pelajaran yang sulit karena kurangnya prototype atau media pembelajaran yang ada (Apriyanto, 2016). Mempelajari matematika lebih lanjut itu harus mempelajari materi matematika sebelumnya. Artinya bahwa, materi matematika harus diberikan secara berurut. Hal ini berlaku juga dalam mempelajari materi bangun ruang.

Materi bangun ruang adalah materi matematika yang didalamnya memuat hitungan, sehingga memerlukan pemahaman lebih. Ini akan membuat para siswa terasa jenuh dan bosan dalam menerima materi pembelajaran. Dengan semakin berkembangnya teknologi khususnya dibidang multimedia dapat dimanfaatkan sebagai media pembelajaran matematika. Dasar memenuhi tuntutan tersebut sejalan dengan perkembangan ilmu pengetahuan dan teknologi, khususnya dalam bidang pendidikan, penggunaan media pembelajaran menjadi semakin beragam dan interaktif, salah satunya yang sedang marak saat ini adalah dengan memanfaatkan teknologi Augmented Reality (AR).

Augmented Reality (AR) adalah bidang penelitian komputer yang menggabungkan data grafis 3D dengan dunia nyata atau dengan kata lain realita yang ditambahkan ke suatu media. Media ini dapat berupa kertas, sebuah marker atau penanda melalui perangkat-perangkat input tertentu. Adanya perpaduan teknologi modern yaitu visualisasi 3D dalam hal ini peneliti menggunakan Augmented Reality, maka bangun ruang yang akan diajarkan guru kepada siswa akan terasa lebih menarik dan membuat siswa dapat memahami bentuk dan rumus-rumus dari bangun ruang tersebut.

\section{KAJIAN PUSTAKA}

\section{Belajar}

Menurut Sardiman (2011) belajar adalah berubah. Belajar berarti mengubah individu yang belajar, bukan saja yang berkaitan dengan penambahan ilmu pengetahuan, akan tetapi juga terbentuknya kecakapan, keterampilan, sikap, pengertian, harga diri, minat, watak, dan penyesuaian diri. Dengan kata lain belajar adalah serangkaian kegiatan jiwa raga, psiko fisik untuk menuju ke perkembangan pribadi manusia seutuhnya, yang berarti menyangkut aspek cipta, rasa dan karsa, ranah kognitif, afektif, dan psikomotorik.

\section{Bahan Ajar}

Bahan ajar adalah sumber belajar yang memiliki peranan penting dalam penunjang proses pembelajaran. Menurut Lestari (2013 : 2) bahan ajar adalah seperangkat materi pelajaran yang mengacu pada kurikulum yang digunakan (dalam hal ini adalah silabus perkuliahan, silabus mata pelajaran, dan/atau silabus mata diktat tergantung pada jenis 
pendidikan yang diselenggarakan) dalam rangka mencapai standar kompetensi dan kompetensi dasar yang telah ditentukan.

\section{Media Pembelajaran}

Perkembangan ilmu pengetahuan dan teknologi semakin mendorong upayaupaya pembaharuan dalam pemanfaatan hasil-hasil teknologi dalam proses belajar mengajar. Para guru dituntut agar mampu menggunakan alat-alat yang dapat disediakan oleh sekolah, dan tidak tertutup kemungkinan bahwa alat-alat tersebut sesuai dengan perkembangan dan tuntutan zaman. Guru sekurang-kurangnya dapat menggunakan alat yang murah dan bersahaja tetapi merupakan keharusan dalam upaya mencapai tujuan pengajaran yang diharapkan.Disamping mampu menggunakan alat-alat yang tersedia, guru juga dituntut untuk dapat mengembangkan alat-alat yang tersedia, guru juga dituntut untuk dapat mengembangkan keterampilan membuat media pengajaran yang akan digunakannya apabila media tersebut belum tersedia.

Media Pembelajaran diartikan segala sesuatu yang dapat dipergunakan untuk merangsang pikiran, perasaan, perhatian dan kemampuan atau ketrampilan pebelajar sehingga dapat mendorong terjadinya proses belajar.

Sedangkan menurut Briggs (1977) media pembelajaran adalah sarana fisik untuk menyampaikan isi/materi pembelajaran seperti : buku, film, video dan sebagainya. Kemudian menurut National Education Associaton (1969) mengungkapkan bahwa media pembelajaran adalah sarana komunikasi dalam bentuk cetak maupun pandang-dengar, termasuk teknologi perangkat keras.Pengertian media pembelajaran adalah segala alat pengajaran yang digunakan untuk untuk membantu menyampaikan materi pelajaran dalam proses belajar mengajar sehingga memudahkan pencapaian tujuan tujuan pembelajaran yang sudah dirumuskan.

Untuk itu guru harus memiliki pengetahuan yang cukup tentang media pengajaran, yang meliputi (Hamalik, $1994: 6$ )

a) Media sebagai alat komunikasi guna lebih mengefektifkan proses belajar mengajar;

b) Fungsi media dalam rangka mencapai tujuan pendidikan;

c) Seluk-beluk proses belajar;

d) Hubungan antara metode mengajar dan media pendidikan;

e) Nilai atau manfaat media pendidikan dalam pengajaran;

f) Pemilihan dan penggunaan media pendidikan

g) Berbagai jenis alat dan teknik media pendidikan;

h) Media pendidikan dalam setiap mata pelajaran;

i) Usaha inovasi dalam media pendidikan.

Dengan demikian, dapat disimpulkan bahwa media adalah bagian yang tidak terpisahkan dari proses belajar mengajar demi tercapainya tujuan pendidikan pada umumnya dan tujuan pembelajaran di sekolah pada khususnya.

Kata media berasal dari bahasa Latin medius yang secara harfiah berarti 'tengah', 'perantara' atau 'pengantar'. Dalam bahasa Arab, media adalah perantara atau pengantar pesan dari pengirim kepada penerima pesan. 
Apabila media itu membawa pesan-pesan atau informasi yang bertujuan instruksional atau mengandung maksud-maksud pengajaran maka media itu disebut Media Pembelajaran.

Media pembelajaran dapat dipahami sebagai segala sesuatu yang dapat menyampaikan atau menyalurkan pesan dari sumber secara terencana, sehingga terjadi lingkungan belajar yang kondusif dimana penerimanya dapat melakukan proses belajar secara efisien dan efektif (Rayanda Asyar 2012 : 8).

Sukiman (2012 : 29) juga memaparkan bahwa media pembelajaran adalah segala sesuatu yang dapat digunakan untuk menyalurkan pesan dari pengirim ke penerima sehingga merangsang pikiran, perasaan, perhatian, dan minat serta kemauan peserta didik sedemikian rupa sehingga proses belajar terjadi dalam rangka mencapai tujuan pembelajaran secara efektif.

\section{Android Sebagai Media Ajar}

Android sangat menunjang pembelajaran dengan berbagai fitur yang telah disediakan. Semua fitur-fitur yang tersedia sangat bermanfaat untuk membantu siswa memahami materi pembelajaran, sehingga guru tidak perlu menjelaskan secara berulang-ulang siswa dapat lebih mudah memahami materi pembelajaran melalui media. Selain itu siswa cenderung lebih suka belajar dengan media dibanding hanya dengan mendengarkan penjelasan dari guru, siswa akan lebih sulit dalam memahami apa yang disampaikan (Fansury, 2017).

Guru harus dapat memilih jenis media atau fitur-fitur yang akan digunakan dalam pembelajaran agar proses belajar mengajar dapat maksimal. Untuk dapat menggunakan aplikasi Android sebagai media pembelajaran guru harus mengetahui sedikitnya 6 hal agar penggunaan Android sebagai media pembelajaran dapat maksimal dan benar-benar dapat menunjang proses pembelajaran. Selain itu guru juga harus mampu mengatasi dampak negatif dari penggunaan Android sebagai media pembelajaran misalnya dengan mengawasi sang murid dalam menggunakan aplikasi yang ada di Android agar tujuan tidak melenceng ke arah yang tidak diinginkan. Dengan begitu tujuan pembelajaran dapat tercapai dan proses pembelajaran tidak akan terganggu. Seorang guru juga seharusnya melakukan kombinasi dalam model mengajarnya sehingga tetap kreatif.

\section{Bangun Ruang}

Bangun ruang adalah bangun matematika yang mempunyai isi atau volume. Bangun ruang merupakan sebuah bangun yang memiliki ruang yang dibatasi oleh beberapa sisi. Jumlah dan model sisi yang membatasi bangun tersebut menentukan nama dan bentuk bangun tersebut. Macam-macam bangun ruang sederhana meliputi Balok, Kubus, Tabung, Bola dan Kerucut. (Listy, 2017).

\section{Media Tiga Dimensi}

Menurut H. Ryandra Ashar media tiga dimensi memiliki arti sebuah media yang tampilannya dapat diamati dari arah pandang mana saja dan mempunyai dimensi panjang, lebar dan tinggi/tebal, kebanyakan merupakan objek sesungguhnya (real object). Sedangkan menurut Moedjiono bahwa media tiga dimensi memiliki beberapa kelebihan diantaranya dapat menunjukkan objek secara utuh baik konstruksi maupun 
cara kerja, dapat emmberikan pengalaman secara langsung, penyajiannya secara konkrit dan menghindari verbalisme.

\section{Augmented Reality}

Augmented Reality merupakan upaya penggabungan dunia nyata dengan dunia virtual yang dibuat melalui komputer sehingga batas antara keduanya sangat tipis. (Mukhlis, 2012). Augmented Reality (AR) adalah variasi dari Virtual Enviroment (VE) atau yang lebih dikenal dengan Virtual Reality (VR), sedangkan virtual reality memiliki arti sebuah situasi dimana pengguna secara keseluruhan berada di dalam lingkungan maya. Ketika berada di lingkungan itu pengguna sendiri tidak dapat melihat dunia nyata disekitarnya. Berbeda dengan AR yang masih dapat melihat dunia nyata dan objek maya hanya ditampilkan ke lingkungan nyata. Oleh karena itu, AR hanya sebagai tambahan realitas dan bukan menggantikannya (Pamodji, 2012).

\section{METODE PENELITIAN}

Penelitian dan pengembangan aplikasi Bangun Ruang menggunakan metode penelitian Research and Development (R\&D) yaitu metode penelitian yang bertujuan menghasilkan produk tertentu serta menguji efektivitas produk tersebut.

Produk yang dihasilkan adalah aplikasi augmented reality, yakni aplikasi untuk media pembelajaran bangun ruang berbasis android menggunakan teknologi augmented reality. Target pengguna aplikasi ini adalah anak SMP kelas VIII. Untuk mendapatkan produk yang sesuai, maka dalam pengembangan perangkat lunak perlu berdasarkan model pengembangan tersebut.

Lokasi penelitian dilakukan di SMP Negeri 8 Palopo, Jalan Dr. Ratulangi Kota Palopo. Adapun subjek penelitian dalam penelitian ini adalah guru dan siswa(i) pada SMP Negeri 8 Kota Palopo, untuk sumber data diperoleh secara langsung melalui observasi dan wawancara dengan Guru Matematika di SMP Negeri 8 Palopo. Adapun data yang diperoleh dari hasil wawancara, sistem pembelajaran bangun ruang masih bersifat manual dalam pemberian contohnya dalam bentuk gambar 2D, Siswa (i) belum bisa memahami bentuk 3D dari bangun ruang itu sendiri. Untuk metode pengembangan sistem yang digunakan pada penelitian ini adalah metode waterfall.

\section{HASIL PENELITIAN}

\section{Hasil Pengujian Sistem}

Dalam pembuatan aplikasi AR bangun ruang ini, diperlukan pengujian-pengujian tertentu untuk menguji kemampuan dari sistem yang ada dalam aplikasi ini. Pengujian dilakukan dengan metode Black Box Testing, dimana program diuji coba secara langsung untuk mengetahui bug-bug yang terjadi di dalam aplikasi. Hasil pengujian blackbox testing dapat dilihat pada tabel 1 :

\section{Tabel 1 Hasil pengujian blackbox}

\begin{tabular}{|l|l|l|c|}
\hline \multicolumn{1}{|c|}{ Skenario Pengujian } & \multicolumn{1}{|c|}{ Test Case } & Hasil Yang Diharapkan & Hasil Uji \\
\hline $\begin{array}{l}\text { User mengklik icon } \\
\text { aplikasi di smartphone }\end{array}$ & $\begin{array}{l}\text { Tampilan awal aplikasi } \\
\text { yang pertama kali muncul } \\
\text { pada saat dijalankan }\end{array}$ & $\begin{array}{l}\text { Halaman splash screen dapat } \\
\text { muncul ketika petama kali } \\
\text { aplikasi di jalan, serta } \\
\text { menampilkan loading. }\end{array}$ & Sesuai Harapan (Valid) \\
\hline
\end{tabular}




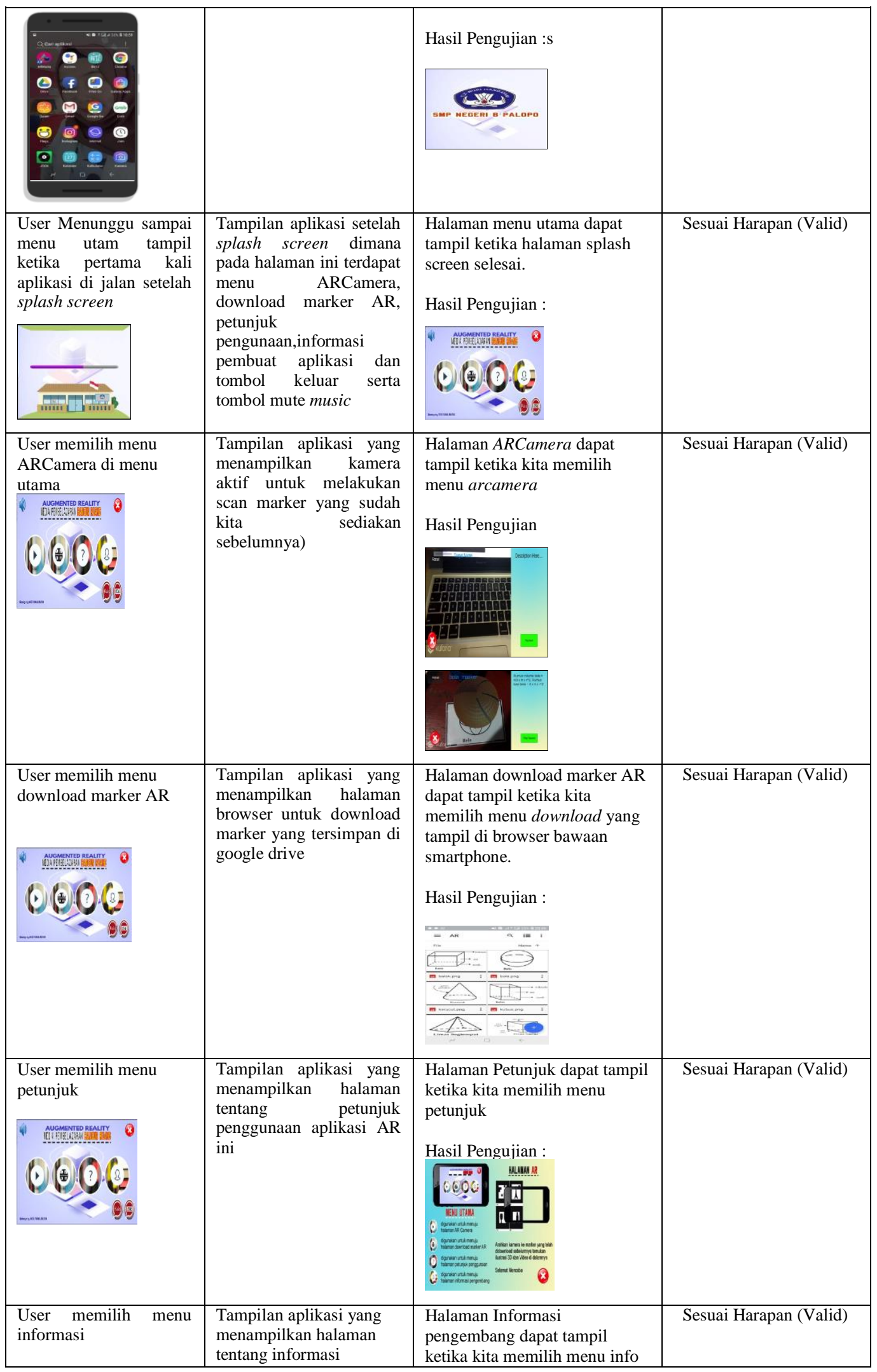




\begin{tabular}{|c|c|c|c|}
\hline (6) $(0)(3)$ & $\begin{array}{l}\text { pembuat aplikasi dan } \\
\text { tentang aplikasi. }\end{array}$ & $\begin{array}{l}\text { Hasil Pengujian } \\
\text { : }\end{array}$ & \\
\hline $\begin{array}{l}\text { User menekan tombol } \\
\text { mute }\end{array}$ & $\begin{array}{l}\text { Tombol yang digunakan } \\
\text { untuk mesilentkan music }\end{array}$ & $\begin{array}{l}\text { Berhasil mematikan music } \\
\text { ketika menu utama tampil. } \\
\text { Hasil Pengujian }\end{array}$ & Sesuai Harapan (Valid) \\
\hline $\begin{array}{l}\text { User menekan tombol } \\
\text { keluar }\end{array}$ & $\begin{array}{l}\text { Tombol yang digunakan } \\
\text { untuk keluar dari aplikasi } \\
\text { AR }\end{array}$ & $\begin{array}{l}\text { Berhasil keluar dari aplikasi } \\
\text { AR bangun Ruang. }\end{array}$ & Sesuai Harapan (Valid) \\
\hline
\end{tabular}

\section{Hasil Pengujian Usability}

Usability termasuk ke dalam pengujian, yakni pengujian dengan metode menguji cobakan langsung hasil aplikasi kepada pengguna. Pengujian usability dilakukan kepada siswa SMP N 8 Kota Palopo kelas VIII.4 sejumlah 25 siswa dan 5 guru saat pembelajaran matematika bangun ruang dengan mencoba langsung aplikasi dan marker AR dan dengan instrumen kuisioner yang dibagikan, hasil pengujian usability dapat dilihat pada Tabel 2 dan Tabel 3.

\section{Table 2 Hasil Pengujian Black Box Testing Aplikasi AR}

\begin{tabular}{llll}
\hline Klasifikasi & Nilai & \multicolumn{2}{c}{ Hasil Angket } \\
\cline { 3 - 4 } & & Frekuensi & Persentasi \\
Sangat Layak & $81-100$ & 25 & 100 \\
Layak & $61-80$ & 0 & 0 \\
Cukup & $41-60$ & 0 & 0 \\
Kurang & $21-40$ & 0 & 0 \\
Sangat Tidak Layak & $1-20$ & 0 & 0 \\
Total & & 25 & 100 \\
\hline
\end{tabular}

Dari hasil pengujian tersebut maka dapat diperoleh detail presentase kelayakan aplikasi sebesar 91\%. Sedangkan untuk persentase kelayakan usability secara keseluruhan adalah sebagai berikut : 
Persentase Kelayakan $(\%)=\frac{\text { Skor Yang Diobservasi }}{\text { Skor Yang Diharapkan }} \times 100 \%$

$$
\begin{aligned}
& =\frac{2396}{2625} \times 100 \% \\
& =91,2
\end{aligned}
$$

Berdasarkan hasil observasi kepada siswa, dapat disimpulkan bahwa aplikasi memenuhi standar usability, yakni sebesar 91\%. Pengujian usability adalah pengujian akhir pada proses pengembangan aplikasi AR Bangun Ruang. Secara bertahap masukan ataupun evaluasi dari user terhadap aplikasi dan marker dapat diperbaiki. Sehingga aplikasi bangun ruang akan mencapai taraf kelayakan yang maksimal.

Untuk pengujian usability untuk guru dapat dilihat pada Tabel 3:

Table 3 Hasil Pengujian Black Box Testing Aplikasi AR

\begin{tabular}{llcc}
\hline Klasifikasi & Nilai & \multicolumn{2}{c}{ Hasil Angket } \\
\cline { 3 - 4 } Sangat Layak & & Frekuensi & Persentasi \\
Layak & $81-100$ & 0 & 0 \\
Cukup & $61-80$ & 0 & 0 \\
Kurang & $41-60$ & 5 & 100 \\
Sangat Tidak Layak & $21-40$ & 0 & 0 \\
Total & $1-20$ & 0 & 0 \\
\hline & & 5 & 100 \\
\hline
\end{tabular}

Dari hasil pengujian tersebut maka dapat diperoleh detail presentase kelayakan aplikasi sebesar 91\%. Sedangkan untuk persentase kelayakan usability secara keseluruhan adalah sebagai berikut :

Persentase Kelayakan $(\%)=$

$$
\begin{aligned}
& \frac{\text { Skor Yang Diobservgsi } 100 \%}{\text { Skor Yang Diharapkan }} \\
= & \frac{272}{300} \times 100 \% \\
= & 91 \%
\end{aligned}
$$

Berdasarkan hasil observasi kepada guru, dapat disimpulkan bahwa aplikasi memenuhi standar usability, yakni sebesar $91 \%$. Pengujian usability adalah pengujian akhir pada proses pengembangan aplikasi AR Bangun Ruang. Secara bertahap masukan ataupun evaluasi dari user terhadap aplikasi dan marker dapat diperbaiki. Sehingga aplikasi bangun ruang akan mencapai taraf kelayakan yang maksimal. 
Berdasarkan hasil pengujian dari kedua obeservasi yang dilakukan kepada siswa dan guru dapat didapat hasil pengujian 91, 02\% dan 90,6\% ini membuktikan bahwa aplikasi media pembelajaran yang dibuat sudah bisa digunakan sebagai media pembelajaran bangun ruang dengan teknologi augmented reality.

\section{KESIMPULAN}

Berdasarkan uraian dari hasil pembahasan maka dapat disimpulkan bahwa pembuatan aplikasi media pembelajaran bangun ruang augmented reality berbasis android dengan metode marker augmented reality sebagai berikut :

1. Berdasarkan hasil pengujian usability yang dilakukan diperoleh hasil $91,02 \%$ dan 90,6 \% ini membuktikan bahwa aplikasi dapat digunakan dan membantu dalam mengilustrasikan objek bangun ruang dalam bentuk 3D.

2. Dalam perancangan aplikasi bangun ruang berbasis augmented reality ini menggunakan metode waterfall. Aplikasi bangun ruang ini mampu membantu siswa-siswi SMP Negeri 8 Kota Palopo dalam memahami konsep bangun ruang dengan ilustrasi 3D dan materi tentang objek bangun ruang yang akan ditampilkan dapat diamati secara langusng dan mudah dipahami. Hal ini didukung dengan hasil pengujan blackbox aplikasi dapat berjalan sesuai dengan yang diharapkan oleh peneliti dan pihak sekolah, dalam hal ini guru dan siswa.

3. Aplikasi bangun ruang ini diimplementasikan pada siswa dan guru dalam proses pembelajaran materi bangun ruang di mata pelajaran matematika.

\section{SARAN}

Berdasarkan dari simpulan dan temuan dari penelitian yang telah dilakukan, maka peneliti memberikan saran sebagai berikut :

1. Augmented reality adalah teknologi yang dapat membuat teknologi interaktif. Sehingga teknologi ini dapat dikembangkan untuk media pembelajaran lain yang membutuhkan ilustrasi tertentu. Karena terbukti dengan penelitian ini siswa menjadi lebih mudah memahami konsep bangun ruang dengan ilustrasi 3D yang disajikan secara AR.

2. Dapat menggunakan metode lain seperti markerless.

3. Menambahkan fitur animasi bergerak 3 dimensi yang lebih menarik agar siswa lebih tertarik belajar melalui aplikasi ini.

Serta menambahkan videoplayback agar pemutar materi dalam bentuk video.

\section{DAFTAR PUSTAKA}

Andriyadi, Anggi. (2011). Augmented reality with ARToolkit. Lampung: Augmented reality Team Arnie, M. Lund. (2011). Use Questionnaire. Diakses dari : http://garyperlman.com/quest/quest.cgi?form=USE pada tanggal 22 Januari 2019. Jam 21.00 WIB.

Apriyanto. (2016). Pengembangan Prototipe Pembelajaran Matematika Komputasi Menggunakan Model Kooperatif Tipe STAD. Jurnal Profesi Pendidik dan 
Tenaga Kependidikan (JPPTK), Vol. 1, No. 3, Hal. 347-360, Juni 2016, ISSN: 2476-9835. Makassar: Global Research and Consulting Institute (Global-RCI). Arsyad, Azhar. (2011). Media Pembelajaran. Jakarta : PT Raja Grafindo Persada. Asyhar, Rayanda. 2012. Kreatif Mengembangkan Media Pembelajaran. Jakarta:Gaung Persada (GP) Press Jakarta.

Awang Harsa, Andi Yusika R, Bagus Satria (2016), Pembelajaran Bangun Ruang Berbasis Augmented Reality Dengan Metode Marker Augmented Reality. https://media.neliti.com/media/publications/237599-pembelajaran-bangunruang-berbasis-augme-89154055.pdf pada tanggal 22 Januari 2019, Jam 20.30 WIB.

Desy Listyaningsih. (2017). Pengembangan Buku Ajar dan Buku Siswa Mata Pelajaran Matematika Kelas 1 Sekolah Dasar Dengan Pendekatan Pendidikan Matematika Realistik Indonesia (PMRI). Skripsi, Universitas Sanata Dharama. Yogyakarta.

Fansury, A., \& Januarty, R. (2017). Model Pembelajaran Picture and Picture Dengan Media Games Android dalam Meningkatkan Kemampuan Kosa Kata Siswa Kelas Vii Smpn 35 Makassar. JKIP (Jurnal Keguruan Dan Ilmu Pendidikan), 4(1), 73-85. Retrieved from https://ojs.fkip.unismuh.ac.id/index.php/jkip/article/view/65

Fathoni, Mochammad. et al. (2012). Alat Musik Perkusi Augmented Reality Berbasis Android. Jurnal Penelitian. Universitas Muhammadiyah Malang.

Hanan, Ridwan Abdul dkk (2018), Desain Bahan Ajar Berbasis Augmented Reality pada Materi Bangun Ruang Bidang Datar, Prosiding SNMPM II, Prodi Pendidikan Matematika, Unswagati, Cirebon, 10 Maret 2018.

Yuniar Supardi (2017), Koleksi Program Tugas Akhir dan Skripsi dengan Android, Elex Media Komputindo, Jakarta

Istiyanto, Jazi E. (2013). Pemrograman Smartphone Menggunakan SDK Android dan Hacking Android. Yogyakarta : Graha Ilmu.

Izzaty, Rita Eka, et al. (2008). Perkembangan Peserta Didik. Yogyakarta : UNY Press. 136

Jogiyanto, HM. “Analisis \& Disain Sistem Informasi”.Andi.Yogyakarta. 2005

Jubilee Enterprise (2016), Blender Untuk Pemula, Yogyakarta, Elex Media Komputindo.

Kemendikbud. (2013). Pemendikbud Nomor 68 Tahun 2013 tentang KD dan Struktur Kurikulum SMP/MI. Jakarta : Menteri Pendidikan dan Kebudayaan Republik Indonesia

Lestari, Ika (2013) Pengembangan Bahan Ajar Berbasis Kompetensi. Padang : Akademia.

Pamoedji, Andre Kurniawan (2017), Mayuni, Ridwan Sanjaya, Membuat Game Augmented Reality (AR) dan Virtual Reality (VR) dengan Unity 3D, Jakarta : Elex Media Komputindo.

Purnama, Mastura Dewi, Muhamad Irfani, Triana Elizabeth (2012), Aplikasi pembelajaran bangun ruang dibuat dengan menggunakan aplikasi Unity 3D, http://eprints.mdp.ac.id/1774/ pada tanggal 22 Januari 2019, Jam 20.30 WIB 
Prastowo, Andi (2015) Panduan Kreatif Membuat Bahan Ajar Inovatif. Jogjakarta : DIVA Press.

Putra, FF., Sari, JN., Suhatman, R, 2012, “Aplikasi Pembelajaran Metamorfhosis Berbasis Android Augmented Reality”, Jurnal Teknik Informatika, Volume 1, Nomor 1, Politeknik Caltex Riau.

Rhesa Septianto (2014), Aplikasi Pembelajaran Bangun Datar Dan Bangun Ruang Berbasis Mobile Android, skripsi Fakultas Komunikasi Dan Informatika Universitas Muhammadiyah, Surakarta

Rosa A.S, M Shalahuddin. "Rekayasa Perangkat Lunak (Terstruktur dan Berorientasi Objek)". Penerbit Modula, Bandung. 2015Santos, M. E. C. et al. (2014). Augmented Reality Learning Experiences: Survey of Prototype Design and Evaluation. IEEE Transactions on learning technologies, 7(1), 3856.

Santyasa, I Wayan. (2007). Landasan Konseptual Media Pembelajaran. Disampaikan dalam Workshop Media Pembelajaran bagi Guru-Guru SMA Negeri Banjar Angkan Pada tanggal 10 Januari 2007 di Banjar Angkan Klungkung. Diakses pada 2 Januari 2019 jam 20.30 WIB

Suharso, Aries. (2012). Model Pembelajaran Interaktif Bangun Ruang 3d Berbasis Augmented Reality. Jurnal Penelitian. Universitas Singaperbangsa Karawang.

Sardiman, A.M. (2011). Interaksi dan Motivasi Belajar Mengajar. Jakarta.(Rajawali Pers.

Sudjana, Nana dan Ahmad Rivai. (2010). Media Pengajaran. Bandung: Sinar Baru Algensindo.

Sukiman. (2012). Pengembangan Media Pembelajaran. Yogyakarta : PT Pustaka Insan Madani

Tim EMS (2015), Pemrograman Android Dalam Sehari, Jakarta : Elex Media Komputindo

Yudhastara, Brian. 2012. Teknologi Augmented Reality Untuk Buku Pembelajaran Hewan pada Anak Usia Dini Secara Virtual. Yogyakarta: STIMIK AMIKOM 